\title{
molecules
}

ISSN 1420-3049

(C) 2007 by MDPI

www.mdpi.org/molecules

Full Paper

\section{Solar Ultraviolet-B Radiation Increases Phenolic Content and Ferric Reducing Antioxidant Power in Avena sativa}

\author{
Christopher T. Ruhland *, Mitchell J. Fogal, Christopher R. Buyarski and Matthew A. Krna \\ Department of Biological Sciences, TS-242 Trafton Sciences Center, Minnesota State University, \\ Mankato, MN 56001, USA; E-mail: christopher.ruhland@mnsu.edu
}

*Author to whom correspondence should be addressed.

Received: 1 May 2007 / Accepted: 26 June 2007 / Published: 29 June 2007

\begin{abstract}
We examined the influence of solar ultraviolet-B radiation (UV-B; 280-320 nm) on the maximum photochemical efficiency of photosystem II $\left(\mathrm{F}_{\mathrm{v}} / \mathrm{F}_{\mathrm{m}}\right)$, bulk-soluble phenolic concentrations, ferric-reducing antioxidant power (FRAP) and growth of Avena sativa. Treatments involved placing filters on frames over potted plants that reduced levels of biologically effective UV-B by either $71 \%$ (reduced UV-B) or by $19 \%$ (near-ambient UV-B) over the 52 day experiment (04 July - 25 August 2002). Plants growing under nearambient UV-B had 38\% less total biomass than those under reduced UV-B. The reduction in biomass was mainly the result of a $24 \%$ lower leaf elongation rate, resulting in shorter leaves and less total leaf area than plants under reduced UV-B. In addition, plants growing under near-ambient UV-B had up to $17 \%$ lower $F_{v} / F_{m}$ values early in the experiment, and this effect declined with plant age. Concentrations of bulk-soluble phenolics and FRAP values were 17 and 24\% higher under near-ambient UV-B than under reduced UV-B, respectively. There was a positive relationship between bulk-soluble phenolic concentrations and FRAP values. There were no UV-B effects on concentrations of carotenoids (carotenes + xanthophylls).
\end{abstract}

Keywords: antioxidant activity, flavonoids, FRAP, total phenols, UV-B 


\section{Introduction}

Terrestrial plants receive relatively large doses of ultraviolet-B radiation (UV-B; $280-315 \mathrm{~nm}$ ) over their lifetime, due to a dependence on photosynthetically active radiation (PAR; 400-700 nm) to drive the light-dependent reactions of photosynthesis. The amount of UV-B incident on a plant is dependent upon spatial and temporal factors such as time of day, seasonality, latitude, altitude, cloud cover, aerosol levels and canopy coverage. Over the past 25 years many studies have examined the effects of ambient and elevated UV-B on terrestrial and aquatic plants (reviewed in [1]). Plant responses to UV$B$ tend to be subtle and species-specific, especially when studies are conducted outside under realistic spectral regimes. Responses to elevated and ambient UV-B include increases in DNA-damage and antioxidant response [2], alterations in plant morphology and architecture [3,4], slight reductions in chlorophyll fluorescence parameters associated with photosystem II [PSII; 5,6] and lower biomass accumulation [7-11]. The most common response of field-grown plants to elevated and ambient levels of UV-B appears to be an increase in concentrations of UV-absorbing phenolics $[1,12,13]$ that may ameliorate potentially damaging UV-B before it reaches sensitive chromophores [14-16]. In addition, it has been proposed that these compounds may act as antioxidants in response to elevated levels of UV-B [17].

The UV-B portion of solar radiation may cause oxidative damage by the formation of reactive oxygen species (ROS) in the forms of superoxide and hydroxyl free radicals, hydrogen peroxide and singlet oxygen [18-20]. The formation and presence of ROS in vivo is difficult to detect and relies upon the use of spin-trapping and electron paramagnetic-resonance spectroscopy [21]. It is therefore easier to measure the effects of oxidative damage after the formation of ROS, which include lipid peroxidation of membranes [22-24], protein and enzyme denaturation [25,26] and DNA damage and repair [2,27]. The chloroplast may be especially sensitive to the formation of oxygen free radicals due to the potential formation of activated oxygen during the light-dependent reactions of photosynthesis $[20,28]$.

Plants contain enzymatic and non-enzymatic antioxidants including superoxide dismutase [2,2931], catalase [32], ascorbic acid and associated metabolites [33], glutathione [29,34,35], tocopherol (vitamin E; [36]), carotenoids [37,38] and phenolics [this issue]). Recently, phenylpropanoids have gained considerable attention as dietary antioxidants [39-43]. Two common classes of these phenolics are the hydroxycinnamic acids (HCA) and flavonoids and it appears that the concentrations of these compounds in vascular plants vary widely. Increased concentrations of these phenolics in response to solar radiation may not only act as a "sunscreen" against potentially damaging UV-B, but may also partially ameliorate damage caused by increased ROS.

In this paper we report the results from an experiment where we manipulated solar UV-B levels reaching potted oat (Avena sativa L. cv. Victory) plants in southern Minnesota. The major HCA of oat have been identified, although very little is known about the flavonoids in this species (reviewed in [44]). We grew plants under filters that either absorbed or transmitted solar UV-B during the summer (04 July - 25 August 2002) to assess the effects of solar UV-B on growth and biomass allocation, chlorophyll fluorescence and the concentration of bulk-soluble phenolics and carotenoids. We used the Ferric Reducing Antioxidant Power (FRAP) assay [40,45] as an antioxidant capacity test. We were particularly interested in whether exposure to ambient UV-B increased the FRAP values of plant 
extracts, and if concentrations of bulk-soluble phenolics and/or carotenoids were related to these values.

\section{Results}

\section{Growth and Biomass}

On 25 August 2002, at the end of the experiment, plants growing under near-ambient UV-B had $38 \%$ less total biomass (0.98 g) than those under reduced UV-B (1.57 g; $P \leq 0.05$; Figure 1$)$. The reduction in biomass under near-ambient UV-B can mostly be attributed to the $38 \%$ reduction in aboveground biomass $(P \leq 0.05)$, with a tendency for a $37 \%$ reduction in root biomass $(P=0.11)$ compared to those under reduced UV-B (Figure 1). Plants under near-ambient UV-B had less living shoots and dead biomass (0.59 and $0.16 \mathrm{~g}$, respectively) than under reduced UV-B (0.95 and $0.26 \mathrm{~g}$, respectively). Total leaf area, calculated from aboveground biomass production and specific leaf mass was $27 \%$ lower on plants growing under near-ambient UV-B than those under reduced UV-B (data not shown). There were no significant UV-B effects on leaf or tiller production between treatments (data not shown).

Figure 1. Effects of UV-B reduction on aboveground and belowground biomass of $A$. sativa under UV-B treatment frames after $52 \mathrm{~d}$. Values are means of individual plants $(\mathrm{n}=10)$. Vertical bars represent $\pm 1 \mathrm{SE}$ and * indicates a significant UV-B treatment effect $(P \leq 0.05)$.

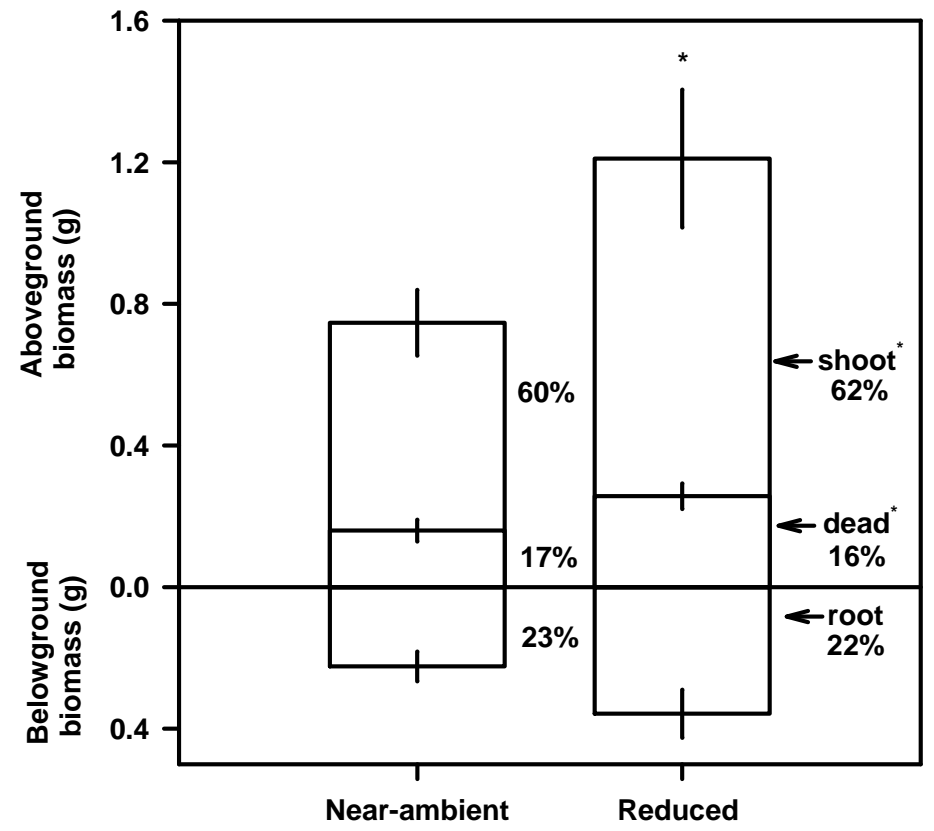

UV-B treatment

Exposure to near-ambient UV-B lowered total plant height, leaf length and leaf elongation rates. Plants growing under near-ambient UV-B were $17 \%$ shorter $(P \leq 0.05$; Figure $2 \mathrm{a})$, blade lengths were $11 \%$ smaller (Figure $2 b$ inset) and had up to a $24 \%$ lower leaf elongation rate $(P \leq 0.05$; Figure $2 b)$ than those under reduced UV-B. Based upon repeated measures ANOVAs the effect of time or census date was significant $(P \leq 0.05)$ on most growth parameters. 
Figure 2. Average (a) total plant height, (b) leaf elongation rate and (c) maximum photochemical efficiency of photosystem II $\left(\mathrm{F}_{\mathrm{v}} / \mathrm{F}_{\mathrm{m}}\right)$ of $A$. sativa during the $52-\mathrm{d}$ experiment. The inset in (b) shows the total blade length of marked leaves. Values are means of individual plants $(n=10)$. Vertical bars denote \pm 1 SE and * indicates a significant UV-B treatment effect $(P \leq 0.05)$.

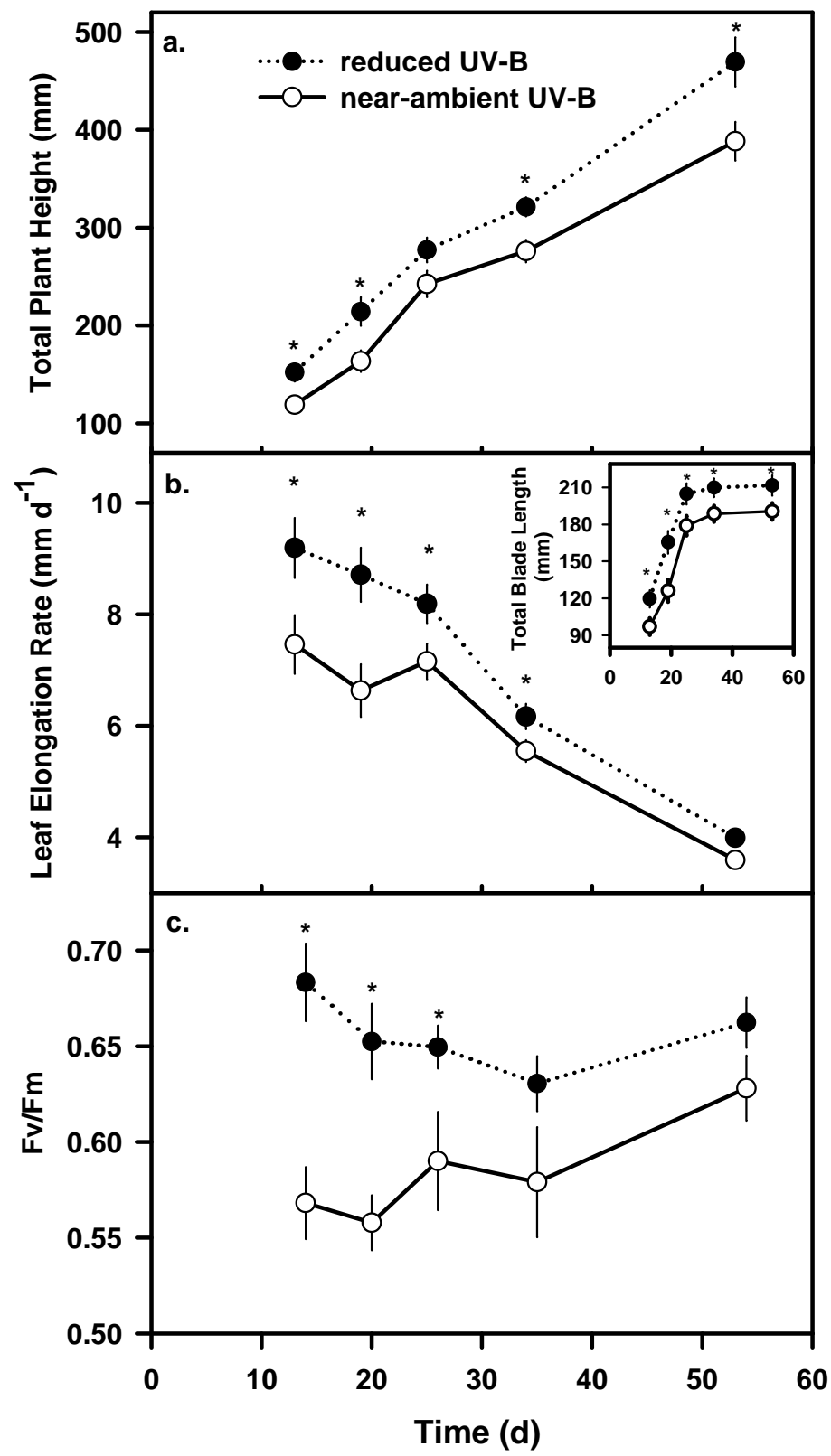

Chlorophyll fluorescence

There was a significant effect of near-ambient UV-B on the maximum photochemical efficiency of PSII $\left(\mathrm{F}_{\mathrm{v}} / \mathrm{F}_{\mathrm{m}}\right)$ on the first three sampling dates $(P \leq 0.05)$. Plants growing under near-ambient UV-B had 9 - 17\% lower $F_{v} / F_{m}$ values than those growing under reduced UV-B (Figure 2c). After $25 \mathrm{~d}$ fluorescence values were higher under the reduced UV-B treatment, but differences between the two treatments were not significant. 
Leaf Chlorophyll, Carotenoids and Bulk-soluble UV-B-absorbing Phenolics

Near-ambient UV-B had no significant effect on total chlorophyll $(a+b)$ or carotenoid (carotenes + xanthophylls) concentrations on a leaf-area basis and averaged 20.6 and $8.0 \mu \mathrm{g} \mathrm{cm}^{-2}$, respectively (data not shown). Concentrations of bulk-soluble phenolics expressed on a leaf-area basis were $17 \%$ higher in plants under near-ambient UV-B than those under reduced UV-B $(P \leq 0.05$; Figure 3a). Concentrations of bulk-soluble phenolics expressed on a dry-mass basis paralleled concentrations on leaf-area basis and were 8\% higher under near-ambient UV-B (data not shown).

Figure 3. Effects of UV-B reduction on (a) concentration of bulk-soluble phenolics and (b) ferric-reducing antioxidant power (FRAP) values of $A$. sativa leaf samples under UVB treatment frames. Values are means of individual plants $(n=10)$. Vertical bars denote \pm 1 SE and * indicates a significant UV-B treatment effect $(P \leq 0.05)$. The inset in (b) shows the significant positive correlation between bulk-soluble phenolic concentrations and FRAP values under both treatments $(P \leq 0.05)$.

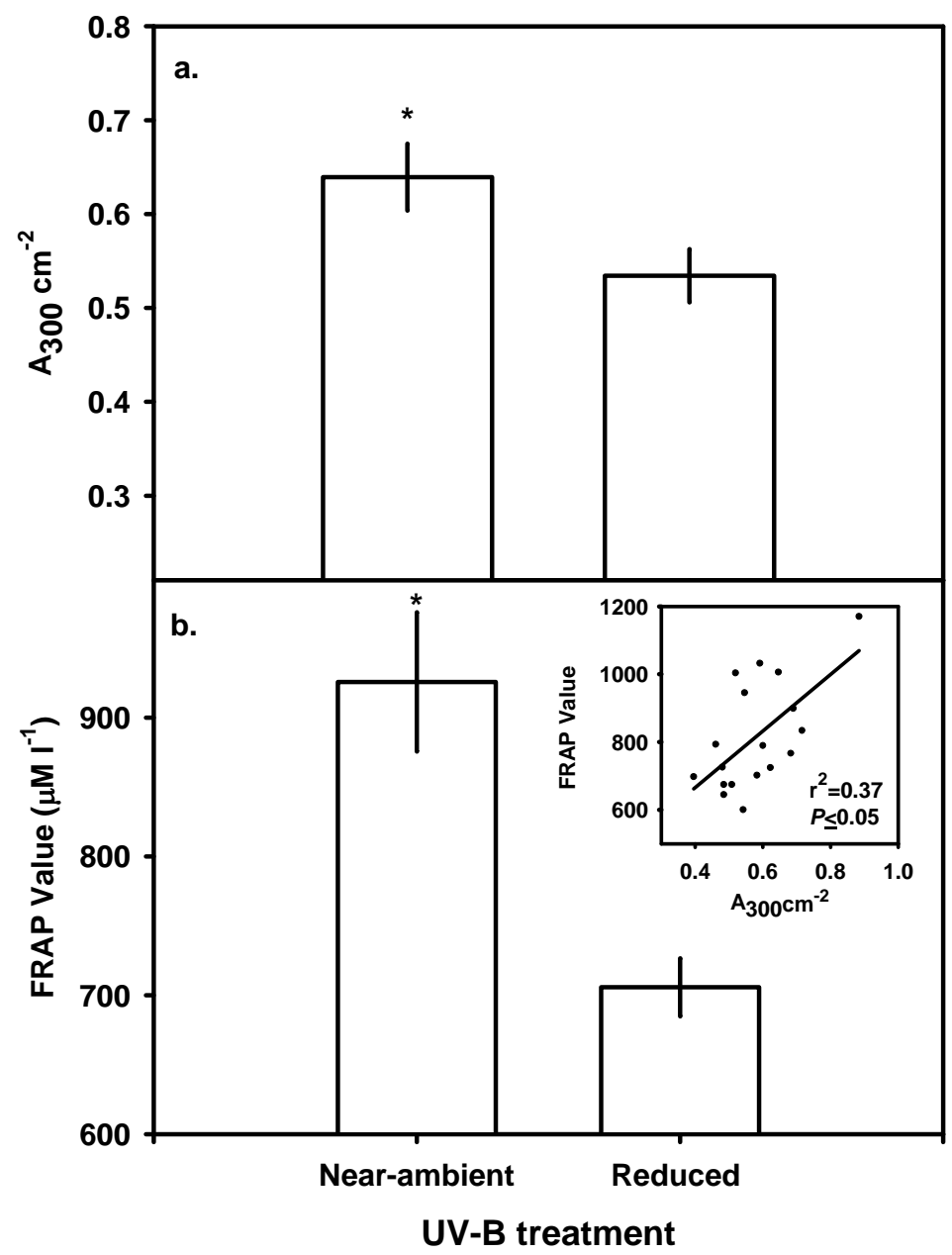


Ferric Reducing Antioxidant Power (FRAP) assay

Methanol extracts of leaves exposed to near-ambient UV-B had greater FRAP values than those grown under reduced UV-B ( $P \leq 0.05$; Figure $3 b$ ). Plants growing under near-ambient UV-B had a $24 \%$ higher FRAP value $\left(925.8 \mathrm{mM} \mathrm{l}^{-1}\right.$ ) than those under reduced UV-B (705.8 $\left.\mathrm{mM} \mathrm{l}^{-1}\right)$. A least-squared linear regression was used to examine relationships between concentrations of phenolics and carotenoids to FRAP values. There was a significant, positive relationship between bulk-soluble UVB-absorbing compound concentrations and FRAP values $\left(P \leq 0.05 ; r^{2}=0.37\right.$; Figure $3 b$ inset) that was not observed with concentrations of carotenoids (data not shown).

\section{Discussion}

Exposure to near-ambient UV-B had a large effect on biomass production. We observed a 38\% reduction in total biomass production of $A$. sativa growing under near-ambient UV-B (Figure 1) which was mainly the result of the reduction in aboveground biomass. These results agree with other studies conducted at similar $[2,7,8]$ and higher $[10,11]$ latitudes. The reduction in biomass does not appear to be related to reductions in tiller or leaf production (data not shown) but rather reductions in leaf elongation (Figures 2a and 2b). Exposure to UV-B did not affect allocation patterns as plants under both treatments had similar allocation to aboveground and belowground parts (Figure 1).

Near-ambient UV-B also had a significant effect on photochemical efficiency of PSII of A. sativa. Several indoor studies have concluded that PSII is a sensitive target of UV-B [46,47]; however most outdoor studies under realistic spectral regimes have not detected significant reductions in $F_{v} / F_{m}$ $[9,19]$. Near-ambient UV-B initially reduced $F_{v} / F_{m}$ by $17 \%$ on the first sampling date and the effect decreased as leaves aged (Figure 2c), suggesting that PSII may be more susceptible to UV-B damage in developing foliage when concentrations of UV-B-absorbing phenolics are presumably lower $[48,49]$.

Ultraviolet-B radiation can stimulate key transcripts of enzymes in the phenylpropanoid pathway, most notably phenylalanine ammonia lyase (PAL; [50,51]) and chalcone synthase (CHS; [52,53]). The extraction of bulk-soluble phenolics with methanol is a common parameter measured in many studies examining plant responses to UV-B [1,12,13]. These bulk extracts are measured spectrophotometrically (typically at $300 \mathrm{~nm}$ ) and corrected for leaf area. It has been traditionally inferred that increased concentrations of these compounds on a whole-leaf basis reduce epidermal transmittance of UV-B and thus protect sensitive chromophores located in the mesophyll [15,16,54]. However, a large proportion of these compounds reside deep in the mesophyll, as well as in the adaxial epidermis [48] where they may have additional roles. These bulk-soluble extracts contain high concentrations of HCA and flavonoids $[11,55]$ which could potentially reduce oxidative damage caused by UV-B. Exposure to near-ambient UV-B increased bulk-soluble phenolic concentrations in A. sativa (Figure 3a). We attribute the increase in FRAP values (Figure $3 \mathrm{~b}$ ) to the increased concentration of bulk phenolics in vitro. The major soluble HCA in oat consists of ferulic, caffeic, $p$-coumaric and vannillic acid esters while the major flavonoids consist mainly of apigenin, luteolin, quercetin and kaempferol glycosides (reviewed in [44]).

We also measured concentrations of carotenoids in plant extracts and did not detect any significant UV-B effects on concentration of these compounds. Furthermore, we did not find any significant 
relationships between concentrations of carotenoids and FRAP values. Taken collectively, the upregulation of phenolics in response to solar UV-B may be more important than carotenoids in providing protection against ROS in oat.

The FRAP assay is one of several tests commonly used to analyze total antioxidant activity of biological samples in vitro in food and agricultural studies (reviewed in [56,57]). The assay is a simple electron transfer reaction that is quick, inexpensive and produces repeatable results. The total nonenzymatic defenses present in methanol extracts can then be used to provide an index of resistance to oxidative damage. We are unaware of any previous experiments that have utilized this test in examining increased phenolic content in response to UV-B. Based on our findings, we suggest that the FRAP assay, along with other antioxidant activity assays would be a useful approach in UV-B radiation research. Determining the antioxidant capacity of specific phenolic compounds that are upregulated in response to UV-B needs to be examined in greater detail.

\section{Experimental}

\section{Study Site and Field Manipulations}

The field experiment was conducted on the campus of Minnesota State University, Mankato, MN, USA ( $44^{\circ} 16^{\prime} \mathrm{N}$; $\left.93^{\circ} 99^{\prime} \mathrm{W}\right)$ in an open field under direct sunlight. Twenty arch-shaped frames ( $1 \mathrm{~m} \mathrm{~L} \mathrm{x}$ $0.7 \mathrm{~m} \mathrm{~W}$ x $0.8 \mathrm{~m} \mathrm{H}$ ) were constructed of galvanized steel fencing (10-cm x 10-cm mesh) and were similar to those of Ruhland and Day [58] and Coleman and Day [59]. Frames were oriented in a SE direction and arranged in groups of two by proximity with ten replicate blocks with each block containing two biologically effective UV-B (UV-B $\mathrm{BE}_{\mathrm{BE}}$; [54]; normalized to $300 \mathrm{~nm}$ ) treatments: nearambient UV-B BE $_{\text {("near-ambient UV-B") and reduced UV-B }}$ ("reduced UV-B"). The near-ambient UV-B frames were covered with 0.2 mm-thick Teflon film (type 300A; DuPont Film, Circleville, OH, USA) which transmits most UV-B (sharp transmission cutoff $<270 \mathrm{~nm}$ ) while reduced UV-B frames were covered with 0.2 mm-thick Mylar (GE Polymer Shapes; Minneapolis, MN, USA) which absorbs most UV-B (sharp transmission cutoff $<325 \mathrm{~nm}$ ). Frames were covered with filters but the sides were left open to facilitate air circulation and maintain temperatures near ambient. This design filtered most direct UV-B but allowed some diffuse UV-B through the open sides. We used this approach because recent evidence presented by Bilger et al. [60] suggests that small differences in temperature can influence phenolic concentrations. Diurnal air temperatures under the treatment frames averaged $0.7^{\circ} \mathrm{C}$ higher than ambient and did not differ between treatments.

Diurnal UV-B $\mathrm{B}_{\mathrm{BE}}$ and UV-A were measured under the treatment frames with broadband dosimeters (SKU 430 and 420, Skye, Powys, UK) that were calibrated against a GUV 541 multichannel radiometer (Biospherical Instruments, San Diego, California, USA). Daily UV-B $B_{\mathrm{BE}}$ averaged 81 and $29 \%$ of ambient levels under the near-ambient and reduced UV-B treatments, respectively. Unweighted UV-A averaged 91\% of ambient levels and did not differ between treatments. Photosynthetically active radiation $(400-700 \mathrm{~nm})$ was measured with a quantum sensor (LI-190SA, LiCor; Lincoln, NE, USA) under the near-ambient and reduced UV-B treatments and averaged 87 and $90 \%$, respectively, of ambient levels.

On 30 June 2002 we germinated A. sativa seeds in distilled water with constant aeration for $48 \mathrm{~h}$. Individual germinated seeds were placed in $1892-\mathrm{cm}^{3}$ plastic pots containing potting soil on 04 July 
2002 and one pot was randomly placed under each individual treatment frame. Plants received $0.5 \mathrm{~L}$ of $\mathrm{H}_{2} \mathrm{O}$ every other day. In order to avoid water stress, plants were watered with an additional $0.5 \mathrm{~L}$ on days when air temperature $\geq 30^{\circ} \mathrm{C}$.

\section{Growth and Biomass}

Non-destructive growth measurements were made on A. sativa plants every 10-15 d over the course of the experiment following Ruhland et al. [11]. This involved marking individual leaves with waterproof ink and measuring leaf and blade length. In addition, the total number of leaves (green and dead) and number of tillers produced were recorded. Five growth censuses were conducted over the course of the experiment. On 25 August 2002 we harvested plants for determination of total biomass accumulation. Plants were removed from their pots and aboveground and belowground biomass was separated. Roots were washed thoroughly with water. The aboveground biomass was further separated into vegetative shoots and necrotic (non-green leaf) material. Samples were oven dried at $60^{\circ} \mathrm{C}$ for 48 $\mathrm{h}$ and weighed on an analytical balance.

\section{Chlorophyll Fluorescence}

Measurements of chlorophyll fluorescence were made every 10-14 d over the course of the experiment. Plants were transported from the field site to the laboratory at Minnesota State University mid-morning and dark adapted for 30 min prior to all measurements. Chlorophyll fluorescence was measured with a pulse-modulated fluorometer (FL1PC, Qubit Systems, Kingston, ON, Canada) midlength on the adaxial leaf surface. Minimal fluorescence $\left(\mathrm{F}_{0}\right)$ was obtained by exposing the darkadapted leaf to a weak modulated LED light source (peak at $660 \mathrm{~nm}$; $50 \mathrm{~Hz}$ frequency) with a duration of $4 \mu$ flash $^{-1}$. Maximal fluorescence $\left(F_{\mathrm{m}}\right)$ was obtained by exposing the leaf to a $0.8 \mathrm{~s}$ saturating pulse ( $>2500 \mu \mathrm{mol}^{-2} \mathrm{~s}^{-1}$ PAR) of actinic light. Maximum photochemical efficiency of PSII $\left(\mathrm{F}_{\mathrm{v}} / \mathrm{F}_{\mathrm{m}}\right)$ was measured as the ratio of variable fluorescence $\left(F_{v}=F_{m}-F_{0}\right)$ to $F_{m}$ following Xiong and Day [9].

\section{Leaf Chlorophyll, Carotenoids and Bulk-soluble UV-B-absorbing Phenolics}

Concentrations of total chlorophyll $(a+b)$, carotenoids (carotenes + xanthophylls) and bulk-soluble phenolics were measured on leaves collected on the final harvest. Two $0.86 \mathrm{~cm}^{2}$ samples were collected in the middle of the leaf blade from the most fully expanded (oldest) leaf. Samples were placed in 50-mL Erlenmeyer flasks containing either $15 \mathrm{~mL}$ of methanol for estimation of chlorophyll and carotenoids or $15 \mathrm{~mL}$ of acidified methanol (MeOH-HCl- $\left.\mathrm{H}_{2} \mathrm{O} ; 90: 1: 1 \mathrm{v} / \mathrm{v}\right)$ for estimation of bulksoluble phenolics. Solutions were heated $\left(60^{\circ} \mathrm{C}\right)$ for $10 \mathrm{~min}$, cooled at room temperature for $15 \mathrm{~min}$ and filtered through $90-\mu \mathrm{m}$ mesh screens. Total chlorophyll and carotenoids were estimated by measuring absorbance with a UV/visible spectrophotometer (HP 8452A; Agilent Technologies; Wilmington, DE, USA) following Wellburn [61]. Concentrations of bulk soluble phenolics were estimated by measuring absorbance at $300 \mathrm{~nm}$ following Day et al. [62]. Measuring bulk phenolics using this method provides a good estimation of chemically-determined total phenolics and is highly correlated with the Folin-Ciocalteu colorimetric method [63]. 
Ferric Reducing Antioxidant Power (FRAP) assay

The FRAP assay of Benzie and Strain [45] was modified for measuring total antioxidant activity of methanol extractions of leaves from under the near-ambient and reduced UV-B treatments at the end of the experiment. This assay measures the total antioxidant (reducing) ability of samples using a colorimetric redox reaction between ferric $\left(\mathrm{Fe}^{3+}\right)$ tripyidyltriazine (clear) to ferrous $\left(\mathrm{Fe}^{2+}\right.$ ) tripyidyltriazine (blue) with the addition of an electron. Individual dried leaf samples from each treatment frame were pulverized to a fine powder using a ball mill grinder (SpectraMill, Chemplex Industries, West Palm Beach, FL, USA). Ferric-reducing compounds were extracted from leaves by placing pulverized leaf samples $(0.417 \mathrm{~g})$ in $\mathrm{MeOH}(50 \mathrm{~mL})$ in a dark incubator $\left(4^{\circ} \mathrm{C}\right)$ for $48 \mathrm{~h}$. Solutions were then filtered through 41- $\mu$ m nylon screens and stored in a dark incubator prior to the assay. A working reagent consisting of acetate buffer (pH 3.6, $300 \mathrm{mM}$ ), acidified 2,4,6 tri(2-pyridyl)s-triazine $(10 \mathrm{mM})$ and $\mathrm{FeCl}_{3} \cdot 6 \mathrm{H}_{2} \mathrm{O}(10: 1: 1 \mathrm{v} / \mathrm{v}, 20 \mathrm{mM})$ was prepared the day of the assay. The reaction was measured in a 5-mL quartz cuvette by mixing working reagent $(2.4 \mathrm{~mL})$ with the leafextraction sample $(84 \mu \mathrm{L})$. Production of ferrous tripyidyltriazine was monitored by measuring the change in absorbance at $593 \mathrm{~nm}$ every $15 \mathrm{~s}$ for $4 \mathrm{~min}$. FRAP values were expressed as equivalents of a known standard of iron (II) sulfate heptahydrate (Sigma-Aldrich, St. Louis, MO USA) and expressed in $\mathrm{mM} \mathrm{L}^{-1}$ following Benzie and Strain [45].

\section{Acknowledgements}

We thank Marney Butz and Sonja Christensen for assistance with FRAP assays. This work was supported by a Faculty Research Grant from the College of Graduate Studies and Research at MNSU and by NSF OPP 0230579.

\section{References and Notes}

1. Day, T.A.; Neale, P.J. Effects of UV-B radiation on terrestrial and aquatic primary producers. Ann. Rev. Ecol. Syst. 2002, 33, 371-396.

2. Mazza, C.A.; Battista, D.; Zima, A.M.; Szwarcberg-Bracchitta, M.; Giordano, C.V.; Acevedo, A.; Scopel, A.L.; Ballaré, C.L. The effects of solar ultraviolet-B radiation on the growth and yield of barely are accompanied by increased DNA damage and antioxidant response. Plant Cell Environ. 1999, 22, 61-70.

3. Furness, M.H.; Upadhyaya, M.K.; Ormond, D.P. Seedling growth and leaf surface morphological responses of three rangeland weeds to ultraviolet-B radiation. Weed Sci. 1999, 47, 427-434.

4. Hunt, J.E.; McNeil, D.L. The influence of present-day levels of ultraviolet-B radiation on seedlings of two Southern Hemisphere temperate tree species. Plant Ecol. 1999, 143, 39-50.

5. Pfündel, E.E. Action of visible and UV radiation on chlorophyll fluorescence from dark adapted grape leaves (Vitis vinifera L.). Photosyn. Res. 2003, 75, 29-39.

6. Albert, K.R.; Mikkelsen, T.N.; Ro-Poulsen, H. Effect of ambient versus reduced UV-B radiation on high arctic Salix arctica assessed by measurements and calculations of chlorophyll $a$ fluorescence parameters from fluorescence transients. Physiol. Plant. 2005, 124, 208-226. 
7. Krizek, D.T.; Mirecki, R.M.; Britz, S.J. Inhibitory effects of ambient levels of solar UV-A and UV-B radiation on growth of cucumber. Physiol. Plant. 1997, 100, 189-198.

8. Krizek, D.T.; Britz, S.J.; Mirecki, R.M. Inhibitory effects of ambient levels of solar UV-A and UV-B radiation on growth of cv. New Red Fire lettuce. Physiol. Plant. 1998, 103, 1-7.

9. Xiong, F.S.; Day, T.A. Effect of solar ultraviolet-B radiation during springtime ozone depletion on photosynthesis and biomass production of Antarctic vascular plants. Plant Physiol. 2001, 125, 738-751.

10. Xiong, F.S.; Ruhland, C.T.; Day, T.A. Effect of solar ultraviolet-B radiation on growth of Colobanthus quitensis at Palmer Station, Antarctica. Global Change Biol. 2002, 8, 1146-1155.

11. Ruhland, C.T.; Xiong F.S.; Clark, W.D.; Day, T.A. The influence of ultraviolet-B radiation on growth, hydroxycinnamic acids and flavonoids of Deschampsia antarctica during springtime ozone depletion in Antarctica. Photochem. Photobiol. 2005, 81, 1086-1093.

12. Day, T.A. In Ecosystems and ultraviolet-B radiation; Cockell, C.; Blaustein, A.R., Eds; Springer-Verlag: New York, 2001; Chapter 4, pp. 80-117.

13. Searles, P.S.; Flint, S.D.; Caldwell, M.M. A meta-analysis of plant field studies simulating stratospheric ozone depletion. Oecologia 2001, 127, 1-10.

14. Caldwell, M.M.; Robberecht, R.; Flint, S.D. Internal filters: Prospects for UV-acclimation in higher plants. Physiol. Plant. 1983, 58, 445-450.

15. Day, T.A. Relating UV-B radiation screening effectiveness of foliage to absorbing-compound concentration and anatomical differences in a diverse group of plants. Oecologia 1993, 95, 542550 .

16. Day, T.A.; Howells B.W.; Rice W.J. Ultraviolet absorption and epidermal-transmittance spectra in foliage. Physiol. Plant. 1994, 92, 207-218.

17. Bornman, J.F.; Reuber, S.; Cen, Y.P.; Weissenböck, G. In Ultraviolet radiation as a stress factor and the role of protective pigments. Lumsden, P., Ed.; Cambridge University Press: New York. 1997; pp. 157-168.

18. Heideg, E.; Mano, J.; Ohno, C.; Asada, K. Increased levels of monodehydroascorbate radical in UV-B-irradiated broad bean leaves. Plant Cell Physiol. 1997, 38, 684-690.

19. Heideg, E.; Rosenavist, E.; Váradj, G.; Bornman, J.; Vincze, É. A comparison of UV-B induced stress responses in three barley cultivars. Func. Plant Biol. 2006, 33, 77-90.

20. Galatro, A.; Simontacchi, M.; Puntarulo, S. Free radical generation and antioxidant content in chloroplasts from soybean exposed to ultraviolet-B. Physiol. Plant. 2001, 113, 564-570.

21. Smirnoff, N. The role of active oxygen in the response of plants to water deficit and desiccation. New Phytol. 1993, 125, 27-58.

22. Kramer, G.F.; Norman, H.A.; Krizek, D.T.; Mireki, R.M. Influence of UV-B radiation on polyamines, lipid peroxidation and membrane lipids in cucumber. Phytochemistry 1991, 22, 2101-2108.

23. Malanga, G.; Puntarulo, S. Oxidative responses and antioxidant content in Chlorella vulgaris after exposure to ultraviolet-B radiation. Physiol. Plant 1995, 22, 672-679.

24. Takeuchi, Y.; Fukumoto, R.; Kasahara, H.; Sakaki, T.; Kato, M. Peroxidation of lipids and growth inhibition induced by UV-B radiation. Plant Cell Rep. 1995, 22, 566-670. 
25. Davies, K.J.A. Protein damage and degradation by oxygen radicals. 1. General aspects. J. Biol. Chem. 1987, 262, 9895-9901.

26. Salin, M.L. Toxic oxygen species and protective systems of the chloroplast. Physiol. Plant 1987, 72, 681-689.

27. Halliwell, B.; Gutteridge, J.M.C. Free radicals in biology and medicine. Clarendon Press: Oxford, U.K., 1999.

28. Elstner, E.F. In Active oxygen/oxidative stress and plant metabolism. Pell, E.J.; Steffen, L.K., Ed.; American Society of Plant Physiology: Rockville, MD, 1991; pp. 13-25.

29. Rao, M.V.; Paliyath, G.; Ormrod, DP. Changes in antioxidant enzymes of Arabidopsis thaliana. Plant Physiol. 1996, 110, 125-136.

30. Kliebenstein, D.J.; Monde, R.A.; Last, R.L. Superoxide dismutase in Arabidopsis: An eclectic enzyme family with disparate regulation and protein localization. Plant Physiol. 1998, 118, 637650.

31. Santos, I.; Almeida, J.; Salema R. The influence of UV-B radiation on the superoxide dismutase of maize, potato, sorghum and wheat leaves. Can. J. Bot. 1999, 77, 70-76.

32. Boldt, R.; Scandalios, J.G. Influence of UV-light on the expression of the Cat2 and Cat3 catalase genes in maize. Free Rad. Biol. Med. 1997, 23, 505-514.

33. Smirnoff, N. The function and metabolism of ascorbic acid in plants. Ann. Bot. 1996, 78, 661669.

34. Rennenberg, H. Glutathione metabolism and possible biological roles in higher plants. Phytochem. 1982, 21, 2771-2781.

35. Hausladen, A.; Alscher, R.G. In Antioxidants in higher plants. Alscher, R.G.; Hess, J.K., Eds.; CRC Press: Boca Raton, FL, 1993; pp. 1-30.

36. Hess, J.L. In Antioxidants in higher plants. Alscher, R.G.; Hess, J.K., Eds.; CRC Press: Boca Raton, FL, 1993; pp. 111-134.

37. Burton, G.W.; Ingold, K.U. $\beta$-carotene: an unusual type of lipid antioxidant. Science 1984, 224, 569-573.

38. Demming-Adams, B.; Adams, W.W. In Antioxidants in higher plants. Alscher, R.G.; Hess, J.K., Eds.; CRC Press: Boca Raton FL, 1993; pp. 59-90.

39. Shirley, B.W. Flavonoids in seeds and grains: physiological function, agronomic importance and the genetics of biosynthesis. Seed Sci. Res. 1998, 8, 415-422.

40. Benzie, I.F.F.; Szeto, T.Y.; Strain, J.J.; Tomlinson, J. Consumption of green tea causes rapid increase in plasma antioxidant power in humans. Nutr. Cancer 1999, 34, 83-87.

41. Dixon, R.A.; Steele, C.L. Flavonoids and isoflavonoids- a gold mine for metabolic engineering. Trend. Plant Sci. 1999, 4, 394-400.

42. Duthie, G.C.; Duthie, S.J.; Kyle, J.A.M. Plant polyphenols in cancer and heart disease: implications as nutritional antioxidants. Nutr. Res. Rev. 2000, 13, 79-106.

43. Hagerman, A.E. Polymeric phenolics as antioxidants. Polyphenols Actualites. 2001, 18-23.

44. Peterson, D.M. Oat antioxidants. J. Cereal Sci. 2001, 33, 115-129.

45. Benzie, I.F.F.; Strain, J.J. The ferric reducing ability of plasma as a measure of "antioxidant power": The FRAP Assay. Analyt. Biochem. 1996, 239, 70-76. 
46. Bornman, J.F. Target sites of UV-B radiation in photosynthesis of higher plants. J. Photochem. Photobiol. B: Biol. 1989, 4, 145-156.

47. Melis, A.; Nemson, J.A.; Harrison, M.A. Damage to functional components and partial degradation of photosystem II reaction center proteins upon chloroplast exposure to ultraviolet-B radiation. Biochim. Biophys. Acta. 1992, 1100, 312-320.

48. Day, T.A.; Howells, B.W.; Ruhland, C.T. Changes in growth and pigment concentrations with leaf age in pea under modulated UV-B field treatments. Plant Cell Environ. 1996, 19, 101-108.

49. Ruhland, C.T.; Day, T.A. Changes in UV-B radiation screening effectiveness with leaf age in Rhododendron maximum. Plant Cell Environ. 1996, 19, 740-746.

50. Li, J.Y.; Oulee, T.M.; Raba, R.; Amundons, R.G.; Last, R.L. Arabidopsis flavonoid mutants are hypersensitive to UV-B irradiation. Plant Cell. 1993, 5, 171-179.

51. Liu, L.; McClure, J.W. Effects of UV-B on activities of enzymes of secondary phenolic metabolism in barley primary leaves. Physiol. Plant. 1995, 93, 734-739.

52. Strid, Å. Alterations in expression of defence genes in Pisum sativum after exposure to supplementary ultraviolet-B radiation. Plant Cell Physiol. 1993, 34, 949-953.

53. Jordan, B.R.; James, P.E.; Strid, Å; Anthony, R.G. The effect of ultraviolet-B radiation on gene expression and pigment composition in etiolated and green pea leaf tissue: UV-B-induced changes are gene specific and dependent on developmental stage. Plant Cell Environ. 1994, 17, 45-54.

54. Caldwell, M.M. In Photophysiology. Geise, A.C., Ed.; Academic Press: New York, 1971; Vol. 6, pp. 131-177.

55. Ruhland, C.T.; Day, T.A. Effects of ultraviolet-B radiation on leaf elongation, production and phenylpropanoid concentrations of Deschampsia antarctica and Colobanthus quitensis in Antarctica. Physiol. Plant. 2000, 109, 244-251.

56. Huang, D.; Ou, B.; Prior, R.L. The chemistry behind antioxidant capacity assays. J. Agric. Food Chem. 2005, 53, 1841-1856.

57. Stratil, P.; Bořivoj, K.; Kubán, V. Determination of total content of phenolic compounds and their antioxidant activity in vegetables - Evaluation of spectrophotometric methods. J. Agric. Food Chem. 2006, 54, 607-616.

58. Ruhland, C.T.; Day, T.A. Size and longevity of seed banks in Antarctica and the influence of ultraviolet-B radiation on survivorship, growth and pigment concentrations of Colobanthus quitensis seedlings. Env. Exp. Bot. 2001, 45, 143-154.

59. Coleman, R.S.; Day, T.A. Response of cotton and sorghum to several levels of subambient solar UV-B radiation: a test of the saturation hypothesis. Physiol. Plant. 2004, 122, 362-372.

60. Bilger, W.; Rolland, M.; Nybakken, L. UV screening in higher plants induced by low temperature in the absence of UV-B radiation. Photochem. Photobiol. Sci. 2007, 6, 190-195.

61. Wellburn, A.R. The spectral determination of chlorophylls $a$ and $b$, as well as total carotenoids, using various solvents with spectrophotometers of different resolution. J. Plant Physiol. 1994, 144, 307-313.

62. Day, T.A.; Ruhland, C.T.; Grobe, C.W.; Xiong, F.S. Growth and reproduction of Antarctic vascular plants in response to warming and UV radiation reductions in the field. Oecologia 1999, 119, 24-35. 
63. Levizou, E.; Manetas, Y. Spectrophotometric assessment of leaf UV-B absorbing compounds and chemically determined total phenolic levels are strongly correlated. Can. J. Bot. 2002, 80, 690-694.

Sample Availability: Not available.

(C) 2007 by MDPI (http://www.mdpi.org). Reproduction is permitted for noncommercial purposes. 